\title{
Minimally invasive resection of benign cardiac tumors
}

\author{
Ayman Kenawy, Abdelrahman Abdelbar, Joseph Zacharias \\ Department of Cardiothoracic Surgery, Lancashire Heart Centre, Blackpool Teaching Hospital, Blackpool, UK \\ Contributions: (I) Conception and design: All authors; (II) Administrative support: J Zacharias; (III) Provision of study materials or patients: A Kenawy, \\ A Abdelbar; (IV) Collection and assembly of data: A Kenawy, A Abdelbar; (V) Data analysis and interpretation: All authors; (VI) Manuscript writing: \\ All authors; (VII) Final approval of manuscript: All authors. \\ Correspondence to: Ayman Kenawy. Cardiothoracic Department, Blackpool Teaching Hospital, Whinny Heys Rd, Blackpool, FY3 8NR, UK. \\ Email: ayman.kenawy@nhs.net.
}

\begin{abstract}
Primary cardiac tumours for which surgical resection is the main stay of treatment are rare and present both diagnostic and management challenges. The majority of patients are asymptomatic and one third of those who have symptoms present with vague constitutional symptoms which further complicates the process of early diagnosis. The current state-of-the art multi-modality imaging, routine use of intraoperative transoesophageal echocardiogram (TOE) in most cardiac centres and the tremendous advances of endoscopic adjuncts greatly enhances both the diagnosis and management of those group of patients. The surgical burden of median sternotomy and the contemporary trend towards less invasive surgery urged the necessity for adopting minimally invasive surgery in general and cardiac tumours are no exception. Despite the rarity of theses tumours, minimally invasive resection is successful in the hands of experienced minimally invasive surgeons who employ the same minimal access valve surgery platform to access the tumours in various cardiac chambers and valves with no compromise to the oncological clearance and hence achieve the benefits of minimally invasive surgery without compromising long term outcomes.
\end{abstract}

Keywords: Minimally invasive surgery; cardiac tumors; endoscopic resection of benign cardiac tumors

Submitted Mar 06, 2020. Accepted for publication Sep 18, 2020.

doi: $10.21037 /$ jtd-20-1201

View this article at: http://dx.doi.org/10.21037/jtd-20-1201

\section{Introduction}

The antemortem diagnosis of cardiac tumours were not possible up until the advent of cardiac angiography in 1952. Until that time, it was all autopsy based retrospective diagnosis (1). The journey to successful resection started when Crafoord, the Swedish pioneer surgeon, managed the first successful left atrial myxoma excision using cardiopulmonary bypass (CPB) (2).

The routine use of trans thoracic echocardiogram these days has led to more diagnosis of cardiac tumours in asymptomatic patients (3) which resulted in more surgical experience and use of different surgical approaches, namely, median sternotomy, minimally invasive surgery and robotic surgery to access the various cardiac chambers for tumour extirpation (4-6).

The minimally invasive cardiac surgical procedures for cardiac tumours, has gained popularity over conventional surgery for various reasons mainly patient satisfaction, quick post-operative recovery, decreased length of hospital stay and decreased cost (7-9) with oncological clearance comparable to median sternotomy approach (10).

Despite primary cardiac tumours, for which surgical resection are indicated, are rare (11), it is usually a relatively straight forward procedure for surgeons with well-established minimally invasive practice because they extrapolate the same setup for minimal access valve surgeries where the right and left atria are accessed through right mini-thoracotomy as is mitral and tricuspid setup $(12,13)$ and the aortic valve is accessed through right anterior thoracotomy (ART) (14).

The beauty of minimal access is most pronounced in intraventricular tumours where the ventricles can be accessed through their respective inlet valves namely mitral 


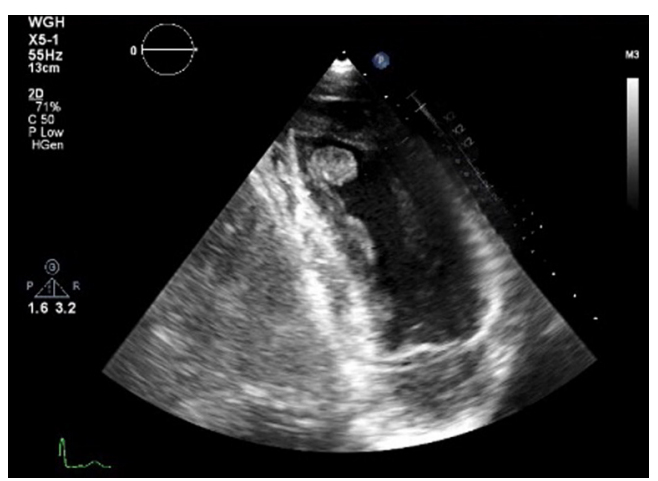

Figure 1 Apical two chamber view of TTE showing left ventricular apical mass. TTE, transthoracic echocardiogram.

and tricuspid for left and right ventricles respectively with greatly enhanced video assisted visualization of the inside of the ventricles (13) instead of the old fashioned median sternotomy and ventriculotomy (15) or access through the outlet valves, aortic (16) and pulmonary for left and right ventricles respectively that carries a risk for damaging those anatomically small area valves compared to the inlet valves.

This article will touch base on the pathology of cardiac tumours, the utility, setup and convenience of minimal access surgery for extirpation of benign cardiac tumours where surgical resection is the mainstay of treatment, the management of primary malignant cardiac tumours and cardiac metastasis is beyond the scope of this article

\section{Pathology of cardiac tumours}

Cardiac tumours are generally rare with an incidence estimated from autopsy studies of $0.001 \%$ to $0.3 \%$ (11), like any tumours, cardiac tumours can be classified into primary and secondary metastatic tumours, with the primary further classified into, benign and malignant tumours.

Secondary cardiac tumours are 30 times $(17,18)$ more common than primary cardiac tumours. Primary tumours are mainly (75\%) benign (19) of which $50 \%$ are cardiac myxoma (11).

Fibroelastoma is the second most common primary tumours with a $10 \%$ incidence of all primary cardiac tumours (20). Both myxoma and fibroelastoma represent most of the surgical practice as far as cardiac tumours are concerned $(11,21)$, other less common benign cardiac tumours includes cardiac lipoma, haemangioma, fibroma and paraganglioma (21).

Malignant cardiac tumours represent $25 \%$ of primary cardiac tumours (19) with cardiac sarcoma being the most common of these tumours (21).

The presentation of primary cardiac tumours is variable, it may well be asymptomatic and picked up during scans done for other reasons or autopsy (11), symptomatic tumours present with one or more of the classic triad of obstruction to flow, embolic phenomena and constitutional symptoms. The size of the tumour governs the degree of its haemodynamic sequalae and the location of the tumour whether left sided or right sided affects which circulation whether systemic or pulmonary can potentially be affected by embolic phenomena. Tumours invading the myocardium may present with arrythmias and those affecting the pericardium present with effusion or tamponade (21).

\section{Pre-operative work up for cardiac tumours}

The rationale beyond investigations when cardiac tumours are suspected is to confirm the diagnosis including the location and the haemodynamic consequences of the tumour. Multi-modality imaging, including two dimensional (2D) transthoracic echocardiogram (TTE), transoesophageal echocardiogram (TOE), computed tomography (CT) scan and magnetic resonance imaging (MRI) are usually necessary to judge tissue characteristics, rule out any cancer elsewhere and to assess the vascular tree from the femoral arteries upstream the aorta to confirm suitability for peripheral access for CPB.

Echocardiography is a non-invasive readily available modality which can assess the site, size, mobility of the tumour added to any valvular abnormality related to the it. It also gives an overall idea about bi-ventricular function and any pericardial effusion (11). Figure 1 shows a 2D, TTE of a left ventricular mass which was incidentally picked up during a routine echocardiogram in our institution, the histology of which turned out to be fibroelastoma.

CT scan is useful to confirm the presence of a mass and its location, it can also differentiate a tumour from other non-tissues masses like thrombus, vegetation, calcium or foreign body (22). The CT is ideal to rule out extra-cardiac tumours and assess the vascular tree for suitability for femoral cannulation and retrograde flow during CPB (23).

MRI scan is more superior to CT scan in terms of tissue characterization. It is also important in case of left atrial myxoma to rule out cerebral metastasis (24), however it is not always convenient to get it done either because of availability issues or contra-indication.

Figure 2 shows an MRI scan of a lady who presented 


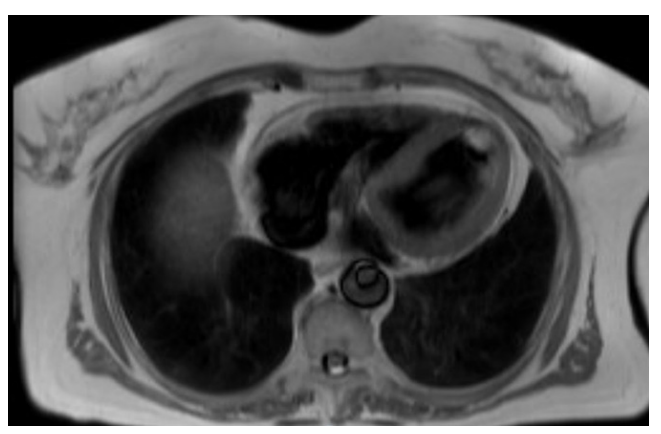

Figure 2 MRI scan showing a mass in the left ventricular apex. MRI, magnetic resonance imaging.

to our institution with a transient ischaemic attack (TIA), she had an echocardiogram as part of the TIA work up which did pick up a left ventricular mass. She subsequently had an MRI scan for tissue characterization of the mass. Interestingly, one of the differential diagnoses of the mass in that lady was metastasis due to a history of bilateral operated breast cancer and because of that relevant history, she had a positron emission tomography (PET) scan which revealed no fluoro-deoxy glucose (FDG) avidity in the mass. she subsequently had MIS excision and the histology revealed to be fibroelastoma.

Coronary angiogram is an important diagnostic procedure before operative intervention to assess the coronary arteries for any significant disease which will need to be addressed before a minimally invasive approach or preclude a MIS as it will need to be addressed at the same time of the tumour excision.

\section{Minimally invasive setup for cardiac tumour excision}

\section{Anaesthetic consideration}

Single lung ventilation is achieved with double lumen tube or a single tube with a bronchial blocker based on the team preference. standard monitoring lines includes electrocardiogram (ECG), pulse oximetry, temperature monitoring, bispectral index (BIS), arterial and central lines with/out Swan-Ganz catheters as appropriate. TOE and defibrillator pads are essentials in MIS in general. If the right atrium is to be opened to excise right atrial tumours or to address concomitant tricuspid valve pathology, a superior vena cava (SVC) cannula is inserted in the anaesthetic room to achieve bicaval cannulation using Seldinger technique and utilizing the internal jugular vein as an entry point.

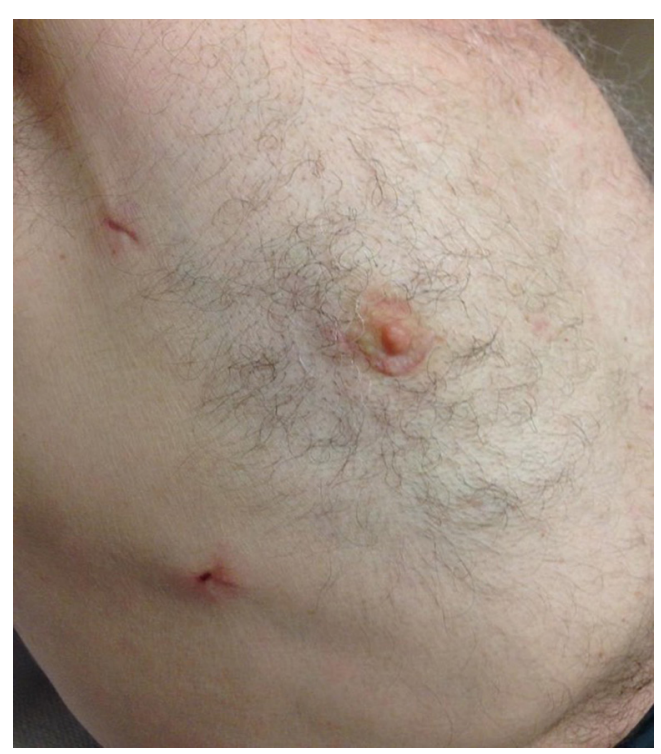

Figure 3 Shows peri-areolar incision to access the 4th intercostal space.

\section{Surgical techniques}

Patient is positioned supine with the right hemithorax tilted up $30^{\circ}$ using a sand bag or inflatable bag., The approach differs according to the target chamber/valve. A right lateral mini-thoracotomy through a peri-areolar incision (Figure 3), is attached with a permission from a patient in our institution who had left ventricular fibroelastoma removed.

Other surgeons do sub-mammary incision in females $(13,25)$ to access the mitral, tricuspid, left and right atria and ventricles. The soft tissues are retracted using (Alexis ${ }^{\circledR}$ ) which is sufficient for totally endoscopic approach with the aid of long shafted instruments (13). Some centres however still apply rib spreading to apply adequate visualization (10).

Other ports required are; one $5 \mathrm{~mm}$ port in the $6^{\text {th }}$ space mid axillary line through which the inferior pericardial stay suture of the lower pericardial edge is passed through it. Also, the CO2 line is fed through it. The same port site acts as the right chest drain site at the end of the operation.

A second $10 \mathrm{~mm}$ port in the $4^{\text {th }}$ or $3^{\text {rd }}$ space mid-axillary line is required for the camera for surgeons who use endoscopic video assisted technique. The same port is used to pass the middle and superior pericardial stay sutures of the lower pericardial edge. The same port is used at the end of the procedure for the pericardial drain. Surgeons who use direct vision use the port as a pass for the pericardial stay sutures and for the pericardial drain at the end. 


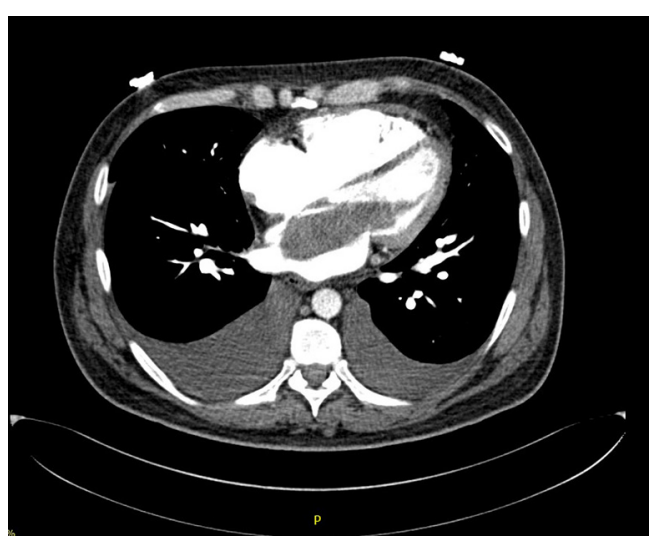

Figure 4 Cardiac CT chest showing large LA myxoma. CT, computed tomography.

A third port in the $2^{\text {nd }}$ space anterior axillary line is used for Chitwood clamp (25). This port is not necessary for surgeons who use intraclude ${ }^{\circledR}$ aortic endoclamp (13).

The aortic valve as well as left ventricular cavity can be accessed through an anterior right thoracotomy (ART) through the second space with disarticulation of the third costal cartilage to facilitate rib spreading (14).

Deairing is usually achieved via left ventricular vent or aortic root vent or both of them based on the procedure

\section{Cannulation strategy and setup for CPB}

Arterial cannulation is mostly through the femoral artery using Seldinger technique and TOE guidance and is either percutaneous or cutdown (14). Some centres are still concerned about retrograde perfusion and use aortic cannulation instead (25). In cases where there is a hostile femoro-iliac arterial system either due to excessive calcification or atheremotous plaques the right axillary artery provides a safe alternative which can either be cannulated directly using Seldinger technique or through an $8 \mathrm{~mm}$ dacron tube graft.

Venous cannulation depends on whether a single dual stage or a bicaval cannulation is required, the former is achieved by a femoral dual stage cannula using Seldinger technique and TOE guidance (14) and is enough for small body surface area (BSA) patients and left sided chambers procedures, SVC cannulation is required in addition to single stage femoral cannulation in cases where the proposed procedure involves opening of the right atrium and this can be achieved either directly (25) or percutaneously as

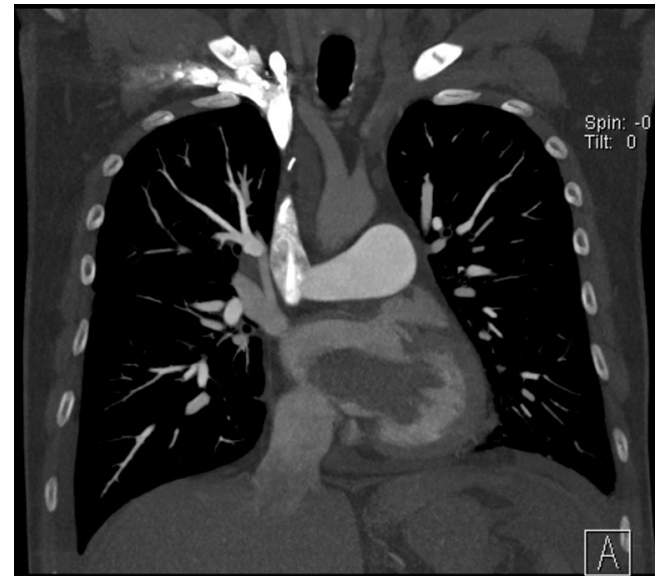

Figure 5 Cardiac CT, Coronal reconstruction of the same patient demonstrating the myxoma prolapsing into the LV through the mitral valve. CT, computed tomography.

referred to in the anaesthetic consideration.

\section{Special considerations}

In case of large atrial myxoma as in Figures 4 and 5 from our institution, care should be taken during manipulating the atria as fragmentation and embolization is a concern.

If the myxoma is in the right atrium the SVC cannula tip should be kept just distal to the superior cavo-atrial junction. This allows applying of a bulldog clamp proximal to the cannula tip. Similarly, the IVC cannula is positioned where the cannula tip is inferior to the inferior cavo-atrial junction allowing snugging the IVC above the cannula tip. This ensures smooth running of CPB by preventing air entering the venous lines.

Another important point during excision of large myxomas is to gently retract it using the cel saver sucker to find the stalk which can be shaved with partial thickness of the atrial or septal wall. The stalk site should be appreciated with the aid of a dynamic imaging modality like, MRI or Intra-operative TOE.

The tumour is then handled from its stalk and fed into a tissue retrieval system to facilitate retrieval through the mini thoracotomy. Alternatively, it can be simply delivered through the incision facilitated by the soft tissue retractor being in place.

Small left ventricular fibroelastomas can be simply shaved off its ventricular attachment and grasped from it base and delivered through the incision as shown in Video 1 
from our institution.

\section{Outcome of minimally invasive surgical resection of cardiac tumours}

The rationale beyond this approach is to get the multitude of benefits of the minimally invasive technique simultaneous with achieving oncological clearance comparable to the conventional median sternotomy. This is regardless of the tumour location or type, as evidenced by immediate disappearance of the tumour on the intraoperative TOE and monitoring of the recurrence rate by regular follow up with echocardiograms.

The established evidence of the safety and the merits of MIS cannot be denied. It is a safe alternative with comparable or superior results in terms of mortality and major morbidity. the long term survival is also excellent (26). It is also associated with decreased resource utilization (27), less blood transfusion and less hospital stay (28). MIS is specially beneficial for the subgroup of patients who are particularly at a high risk for median sternotomy namely the old (29) and the obese patients (30) with evidence of less mortality and morbidity compared to median sternotomy. MIS also increases patient satisfaction with early return to normal life with decreased requirements for rehabilitation services (8).

As far as the location, type and oncological clearance are concerned, Deshpande et al. (13) reported a variety of cardiac tumours including left and right atrial myxoma, papillary fibroelastoma of aortic valve, intravenous leiomyoma involving the inferior vena cava and the tricuspid valve, plexiform tumour of the sinoatrial node, all resected endoscopically with no tumour recurrence on TTE on follow up for a median of $3.4 \pm 2.7$ years. They had no inhospital mortality or new stroke in their 27 patients.

Iribarne et al. (25) compared median sternotomy and minimally invasive techniques in excision of various cardiac tumours. With long term follow up, average 4.8 years, this showed similar hospital mortality, long term survival, and recurrence rate of the tumours. However, the MIS had significantly fewer stroke and hospital stay compared to median sternotomy.

The CPB and cross clamp times tends to be longer in the minimally invasive surgery in general as part of the learning curve. This is not totally applicable to MIS for cardiac tumours as they do not have a learning curve as such. In fact, minimally invasive surgeons extrapolate their experience with valve surgeries to the resection of cardiac tumours which is so evidenced by the small number of cardiac tumours over extended period of time and still with excellent outcomes comparable, if not, superior to median sternotomy approach (25).

Dr. Pineda (14) in his 11-year experience with 22 patients with various tumour types and locations in the minimally invasive group, the CBP but not the cross clamp time was significantly higher in the MIS group compared to the median sternotomy group. However, this seems to be irrelevant as evidenced by the significantly shorter ventilation time, less intensive care (ICU) length of stay and less hospital stay with no difference in mortality or stroke. There was no conversion to median sternotomy in the minimally invasive group over the 9- and 11-year periods of those reports reflecting the experience of the operators in the MIS $(14,25)$.

Over the past 10 years we in Blackpool have resected 20 benign cardiac tumours with no conversion to sternotomy and no in hospital deaths. The majority have been atrial myxomas though we have resected two papillary fibroelastomas from the apex of the left ventricle. Added to the excellent cosmetic results, we have found patients benefit from an early discharge home. We have not had any recurrences in our experience to date suggesting complete excision of the tumours at the time of surgery.

\section{Conclusions}

Minimally invasive resection of cardiac tumours combine the advantages of the minimally invasive surgery with the oncological clearance comparable to median sternotomy provided that it is done by surgeons with well-established minimally invasive surgical practice.

\section{Acknowledgments}

Funding: None.

\section{Footnote}

Provenance and Peer Review: This article was commissioned by the Guest Editors (Jason Ali and Yasir Abu-Omar) for the series "Minimally Invasive Cardiac Surgery" published in Fournal of Thoracic Disease. The article has undergone external peer review.

Conflicts of Interest: All authors have completed the ICMJE uniform disclosure form (available at http://dx.doi. 
org/10.21037/jtd-20-1201). The series "Minimally Invasive Cardiac Surgery" was commissioned by the editorial office without any funding or sponsorship. JZ reports that he is Proctor for Edwards LifeScience, Abbott and Cryolife. The authors have no other conflicts of interest to declare.

Ethical Statement: The authors are accountable for all aspects of the work in ensuring that questions related to the accuracy or integrity of any part of the work are appropriately investigated and resolved.

Open Access Statement: This is an Open Access article distributed in accordance with the Creative Commons Attribution-NonCommercial-NoDerivs 4.0 International License (CC BY-NC-ND 4.0), which permits the noncommercial replication and distribution of the article with the strict proviso that no changes or edits are made and the original work is properly cited (including links to both the formal publication through the relevant DOI and the license). See: https://creativecommons.org/licenses/by-nc-nd/4.0/.

\section{References}

1. Read RC. Cardiac myxoma and surgical history. Ann Thorac Surg 1980;29:395-6.

2. Chitwood Jr WR. Clarence Crafoord and the first successful resection of a cardiac myxoma. Ann Thorac Surg 1992;54:997-8.

3. Fyke FE, Seward JB, Edwards WD, et al. Primary cardiac tumors: experience with 30 consecutive patients since the introduction of two-dimensional echocardiography. J Am Coll Cardiol 1985;5:1465-73.

4. Centofanti P, Di Rosa E, Deorsola L, et al. Primary cardiac tumors: early and late results of surgical treatment in 91 patients. Ann Thorac Surg 1999;68:1236-41.

5. Ravikumar E, Pawar N, Gnanamuthu R, et al. Minimal access approach for surgical management of cardiac tumors. Ann Thorac Surg 2000;70:1077-9.

6. Gao C, Yang M, Wang G, et al. Excision of atrial myxoma using robotic technology. J Thorac Cardiovasc Surg 2010;139:1282-5.

7. McClure RS, Cohn LH, Wiegerinck E, et al. Early and late outcomes in minimally invasive mitral valve repair: An eleven-year experience in 707 patients. J Thorac Cardiovasc Surg 2009;137:70-5.

8. Cohn LH, Adams DH, Couper GS, et al. Minimally Invasive Cardiac Valve Surgery Improves Patient Satisfaction While Reducing Costs of Cardiac Valve
Replacement and Repair. Ann Surg 1997;226:421-6.

9. Poston RS, Tran R, Collins M, et al. Comparison of economic and patient outcomes with minimally invasive versus traditional off-pump coronary artery bypass grafting techniques. Ann Surg 2008;248:638.

10. Bianchi G, Margaryan R, Kallushi E, et al. Outcomes of Video-assisted Minimally Invasive Cardiac Myxoma Resection. Heart Lung Circ 2019;28:327-33.

11. Butany J, Nair V, Naseemuddin A, et al. Cardiac tumours: diagnosis and management. Lancet Oncol 2005;6:219-28.

12. Vistarini N, Alloni A, Aiello M, et al. Minimally invasive video-assisted approach for left atrial myxoma resection. Interact Cardiovasc Thorac Surg 2010;10:9-11.

13. Deshpande RP, Casselman F, Bakir I, et al. Endoscopic Cardiac Tumor Resection. Ann Thorac Surg 2007;83:2142-6.

14. Pineda AM, Santana O, Zamora C, et al. Outcomes of a minimally invasive approach compared with median sternotomy for the excision of benign cardiac masses. Ann Thorac Surg 2011;91:1440-4.

15. Samuels LE, Curran S, Carr R. Left ventricular apical papillary fibroelastoma. J Thorac Cardiovasc Surg 2012;143:974.

16. Toeg HD, Cusimano RJ. Left ventricular apical papillary fibroelastoma resection via mediastinoscope through the aortic valve. Innovations 2012;7:452-3.

17. Bussani R, De-Giorgio F, Abbate A, et al. Cardiac metastases. J Clin Pathol 2007;60:27-34.

18. Goldberg AD, Blankstein R, Padera RF. Tumors metastatic to the heart. Circulation 2013;128:1790-4.

19. Bakaeen FG, Reardon MJ, Coselli JS, et al. Surgical outcome in 85 patients with primary cardiac tumors. Am J Surg 2003;186:641-7.

20. Bruckner BA, Reardon MJ. Benign cardiac tumors: a review. Methodist Debakey Cardiovasc J 2010;6:20-6.

21. Yanagawa B, Chan EY, Cusimano RJ, et al. Approach to Surgery for Cardiac Tumors: Primary Simple, Primary Complex, and Secondary. Cardiol Clin 2019;37:525-31.

22. de Lucas EM, Pagola MÁ, Fernández F, et al. Primary cardiac lymphoma: helical CT findings and radiopathologic correlation. Cardiovasc Intervent Radiol 2004;27:190-1.

23. Leonard JR, Henry M, Rahouma M, et al. Systematic preoperative CT scan is associated with reduced risk of stroke in minimally invasive mitral valve surgery: A metaanalysis. Int J Cardiol 2019;278:300-6.

24. Wan Y, Du H, Zhang L, et al. Multiple cerebral metastases and metastatic aneurysms in patients with left atrial Myxoma: a case report. BMC Neurol 2019;19:249. 
25. Iribarne A, Easterwood R, Russo MJ, et al. LongTerm Outcomes With a Minimally Invasive Approach for Resection of Cardiac Masses. Ann Thorac Surg 2010;90:1251-5.

26. Mihaljevic T, Cohn LH, Unic D, et al. One thousand minimally invasive valve operations: early and late results. Ann Surg 2004;240:529-34.

27. Doll N, Borger MA, Hain J, et al. Minimal access aortic valve replacement: Effects on morbidity and resource utilization. Ann Thorac Surg 2002;74:S1318-22.

28. Bakir I, Casselman FP, Wellens F, et al. Minimally

Cite this article as: Kenawy A, Abdelbar A, Zacharias J. Minimally invasive resection of benign cardiac tumors. J Thorac Dis 2021;13(3):1993-1999. doi: 10.21037/jtd-20-1201
Invasive Versus Standard Approach Aortic Valve Replacement: A Study in 506 Patients. Ann Thorac Surg 2006;81:1599-604.

29. Lamelas J, Sarria A, Santana O, et al. Outcomes of Minimally Invasive Valve Surgery Versus Median Sternotomy in Patients Age 75 Years or Greater. Ann Thorac Surg 2011;91:79-84.

30. Santana O, Reyna J, Grana R, et al. Outcomes of Minimally Invasive Valve Surgery Versus Standard Sternotomy in Obese Patients Undergoing Isolated Valve Surgery. Ann Thorac Surg 2011;91:406-10. 